Check for updates

Cite this: RSC Adv., 2018, 8, 42049

Received 2nd August 2018

Accepted 29th November 2018

DOI: $10.1039 / \mathrm{c} 8 \mathrm{ra06504g}$

rsc.li/rsc-advances

\section{Sn-doped 3D ATO inverse opal/hematite hierarchical structures: facile fabrication and efficient photoelectrochemical performance $\dagger$}

\author{
Junjie Zhang, Jing Li, Boxue Zhang, Jianfeng Ye, (D) Yun Wang (D)* \\ and Xiaozhou Ye (iD *
}

The coupling of hematite with a three-dimensional (3D) conductive inverse opal (IO) skeleton provides an efficient route to enhance the photoelectrochemical (PEC) properties of hematite without changing its chemical composition. In this work, novel 3D antimony-doped $\mathrm{SnO}_{2}$ (ATO) IO/hematite heterostructures were facilely fabricated, and their PEC properties were thoroughly studied. Analysis of the morphologies and photocurrent densities of the 3D ATO $1 \mathrm{O} / / \mathrm{Fe}_{2} \mathrm{O}_{3}$ heterostructures reveals that the high conductivity of the ATO skeleton as well as the high specific area and good light harvesting properties of the 3D IO structures greatly enhance their PEC performance. In particular, further morphology tuning by changing the diameters of the ATO IO skeletons could optimize the optical and electrical properties of the as-prepared heterostructures, demonstrating the important influence of morphology engineering on PEC performance. Moreover, after a simple Sn-doping process, the PEC properties of the as-prepared structure could be further enhanced; a photocurrent density of $1.28 \mathrm{~mA} \mathrm{~cm}^{-2}$ at $1.23 \mathrm{~V}$ vs. RHE was obtained under AM 1.5G illumination.

\section{Introduction}

With increasing concerns regarding the greenhouse effect and the global energy crisis, photoelectrochemical (PEC) water splitting has attracted worldwide attention as a promising solution to address these environmental and energy issues. ${ }^{1,2}$ Since $\mathrm{TiO}_{2}$ was first used as a photoelectrode for PEC water splitting as reported by Fujishima and Honda in 1972, ${ }^{3}$ numerous other semiconductors have been studied as possible candidates, such as $\mathrm{CdS},{ }^{4} \mathrm{WO}_{3},{ }^{5}$ and $\mathrm{BiVO}_{4},{ }^{6}$ and they have exhibited promising PEC performance. Among these, hematite has attracted particular attention due to its suitable band gap $\left(E_{\mathrm{g}}=2.2 \mathrm{eV}\right)$ for efficient light absorption, excellent chemical stability for resistance to photocorrosion, and a high theoretical water splitting efficiency of around $12.4 \% .^{7-9}$ However, the reported PEC properties of hematite-based photoanodes are very different from those of theoretical models; this may be due to several drawbacks presented by intrinsic factors of hematite, such as low absorption coefficients, short hole diffusion lengths ( 2 to $4 \mathrm{~nm}$ ), short photo-generated charge carrier lifetimes ( $<10$ ps), and poor electrical conductivity. ${ }^{10,11}$

Many strategies have been developed to solve those problems and enhance the PEC properties of hematite-based anodes. Among these, element doping, such as doping with $\mathrm{Ti}$, Sn, or Si,

Department of Chemistry, College of Science, Huazhong Agricultural University, Wuhan 430070, China.E-mail: xzye@mail.hzau.edu.cn; yunwang123@126.com

$\dagger$ Electronic supplementary information (ESI) available. See DOI: $10.1039 / \mathrm{c} 8 \mathrm{ra06504g}$ can improve the electron conductivity of hematite and hence improve the charge transfer of hematite electrodes. ${ }^{12-14}$ In particular, Sn ions can be readily incorporated into hematite due to their similar ionic radius and Pauling electronegativity to $\mathrm{Fe}$ ions. ${ }^{15}$ It was found that Sn-doping is effective to improve the electronic conductivity of hematite., ${ }^{9,15}$ Also, Sn incorporation can change the morphology ${ }^{16,17}$ and surface of hematite, ${ }^{18}$ resulting in decreased electron-hole recombination and additional enhancement of PEC performance. ${ }^{18-20}$

In addition to element doping, constructing hematite compositions with nanostructured electron-conductive substrates has received much attention. ${ }^{21}$ By depositing hematite thin films or nanoparticles on nanostructured substrates of conductive materials, the charge transfer properties of hematite can be greatly improved, and electron-hole recombination loss can be decreased. ${ }^{8}$ Transparent conducting oxides (TCO), such as F-doped $\mathrm{SnO}_{2}$ (FTO), Sb-doped $\mathrm{SnO}_{2}$ (ATO), and Al-doped ZnO (AZO), have advantages of profound electronic conductivity and high transparency in the visible region of the spectrum; they are perfect candidates for hosting hematite to construct composite photoanodes for water splitting. ${ }^{22,23}$ In this regard, ITO nanowire arrays, ${ }^{24}$ FTO nanocone arrays, ${ }^{25,26}$ ATO nanorod arrays, ${ }^{27}$ and ATO 3D skeletons ${ }^{28}$ have been used as nanostructured conductive substrates on which to deposit hematite nanoparticles or thin films, and the resulting heterostructures exhibit greatly enhanced PEC properties compared to pristine hematite.

In addition, the morphologies of the heterostructures can be designed and tuned to increase the interfacial area of hematite 
and the electrolyte and facilitate light absorption to further enhance the PEC properties. ${ }^{26}$ The 3D inverse opal (IO) structure is the inverse replica of $3 \mathrm{D}$ colloidal crystal. ${ }^{29}$ Due to its periodically ordered macroporous structures, 3D IOs have photonic effects, where the light absorption in specific wavelength regions can be strongly enhanced by altering the diameter of the IOs. ${ }^{5,30}$ Hence, 3D IO structures are widely employed to construct photoanodes to improve their light utilization performance. ${ }^{5,31}$ For example, Liu et al. ${ }^{32}$ fabricated $\mathrm{SrTiO}_{3} 3 \mathrm{D}$ inverse opals with different pore sizes and investigated their water splitting properties. The overlap of the photonic stopband with its band gap was achieved by choosing suitable pore sizes for the IO structures. As a result, compared with disordered porous $\mathrm{SrTiO}_{3}$, notably enhanced efficiency of water splitting of 3DOM $\mathrm{SrTiO}_{3}$ was realized due to the slow photon effect.

On the other hand, it has been well-documented that $3 \mathrm{D}$ inverse opal structures can also provide favorable charge transport properties $^{4}$ due to their ordered interconnected macropores. ${ }^{33}$ In addition, 3D inverse opal structures have relatively large surface areas without accelerating charge recombination. ${ }^{34,35}$ For example, $3 \mathrm{D}$ graphene inverse opal was fabricated on FTO and used as a substrate on which to deposit hematite. ${ }^{36}$ The photocurrent density of $\alpha-\mathrm{Fe}_{2} \mathrm{O}_{3} / \mathrm{GIO}$ in water splitting is 1.4 times greater than that of hematite. It was confirmed that the improvement was due to decreased electron-hole recombination and the shortened charge transfer distance between hematite and the conducting graphene substrate. There are also several studies on the fabrication of 3D IO ATO and hematite host-guest structures, ${ }^{28,37}$ which exhibit improved PEC properties. However, for these IO heterostructures, there are few studies discussing their morphology-related light utilizing properties and PEC properties. Herein, we report the fabrication of ATO IO/ $/ \mathrm{Fe}_{2} \mathrm{O}_{3}$ composite structures with PEC properties. In this photoanode design, the highly conductive ATO IO acts as an effective conductive skeleton and provides a relatively high surface area for loading of photoactive hematite, which provides fast and direct electrical transport paths. In addition, to further investigate the influence of the morphologies of the heterostructures on their light harvesting and PEC properties, ATO $\mathrm{IO} / \mathrm{Fe}_{2} \mathrm{O}_{3}$ composite structures with three different diameters were designed and fabricated. As a result, the as-fabricated 3D ATO IO/ $\mathrm{Fe}_{2} \mathrm{O}_{3}$ composite structures with suitable pore diameters presented enhanced PEC performance, achieving $1.04 \mathrm{~mA} \mathrm{~cm}^{-2}$ at $1.23 \mathrm{~V} v s$. RHE, which is 8 times that of the reference planar ATO/ $\mathrm{Fe}_{2} \mathrm{O}_{3}$ sample. Moreover, we further enhanced the photocurrent densities of the samples by Sn-doping, and the enhancement mechanism was also studied.

\section{Experimental}

\section{Materials}

All chemicals used were of analytical grade. Tin(Iv) chloride pentahydrate $\left(\mathrm{SnCl}_{4} \cdot 5 \mathrm{H}_{2} \mathrm{O},>99.7 \%\right)$, iron trichloride hexahydrate $\left(\mathrm{FeCl}_{3} \cdot 6 \mathrm{H}_{2} \mathrm{O},>99.0 \%\right)$, antimony(III) chloride $\left(\mathrm{SbCl}_{3}\right.$, $>99.0 \%$ ), sodium nitrate $\left(\mathrm{NaNO}_{3},>99.0 \%\right)$, sodium hydroxide $(\mathrm{NaOH},>96.0 \%)$, and ethanol $(>99.7 \%)$ were obtained from
Sinopharm Chemical Reagent Co., Ltd. Fluorine-doped tin oxide (FTO) coated glass $\left(<14 \Omega \mathrm{sq}^{-1}, 2.2 \mathrm{~mm}\right.$ thick) was obtained from Wuhan Jinge Solar Energy Technology Co., Ltd.

\section{Preparation of ATO IO/Fe $\mathrm{Fe}_{2} \mathrm{O}_{3}$ structures and planar $\mathrm{ATO} / \mathrm{Fe}_{2} \mathrm{O}_{3}$ films}

The fabrication process of the ATO IO/ $\mathrm{Fe}_{2} \mathrm{O}_{3}$ structures is presented in Scheme 1. Firstly, ATO inverse opals (IO) were prepared by modified drop casting methods. ${ }^{5}$ Typically, polystyrene spheres (PS) with diameters of 220, 330, and $670 \mathrm{~nm}$ were assembled on fluorine-doped tin dioxide (FTO) substrates $(1 \mathrm{~cm} \times 2.5 \mathrm{~cm})$ using a vertical deposition technique ${ }^{38}$ to form

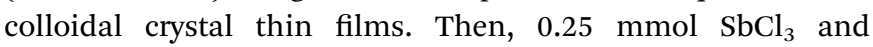
$0.75 \mathrm{mmol} \mathrm{SnCl}_{4} \cdot 5 \mathrm{H}_{2} \mathrm{O}$ were both dissolved in $5 \mathrm{~mL}$ absolute ethanol, yielding a translucent precursor solution. The final concentrations of $\mathrm{SbCl}_{3}$ and $\mathrm{SnCl}_{4} \cdot 5 \mathrm{H}_{2} \mathrm{O}$ were $0.05 \mathrm{M}$ and $0.15 \mathrm{M}$, respectively. Then, $10 \mu \mathrm{L}$ precursor solution was dropped on the colloidal crystal template and subsequently dried in a $100{ }^{\circ} \mathrm{C}$ oven. After the film was cooled to room temperature, the same procedure was repeated. The colloidal crystal templates were then removed by high temperature annealing at $500{ }^{\circ} \mathrm{C}$ for $2 \mathrm{~h}$ under ambient air, and ATO IO films were obtained.

Secondly, a $\mathrm{Fe}_{2} \mathrm{O}_{3}$ layer was coated on the ATO IO films by a hydrothermal reaction. Typically, $0.8 \mathrm{mmol} \mathrm{FeCl}_{3} \cdot 6 \mathrm{H}_{2} \mathrm{O}$ and $1.6 \mathrm{mmol} \mathrm{NaNO}_{3}$ were dissolved in $20 \mathrm{~mL}$ distilled water to obtain a yellow solution. Then, the solution was transferred into a $25 \mathrm{~mL}$ Teflon-lined stainless steel autoclave, and the asprepared ATO IO films were also placed in the autoclave vertically. The reaction was carried out in a $120^{\circ} \mathrm{C}$ oven for $2 \mathrm{~h}$. After the reaction, a thin layer of akaganeite phase (FeOOH) nanoparticles was grown on the ATO IO skeleton. ${ }^{39}$ The obtained ATO $\mathrm{IO}(330) / \mathrm{FeOOH}$ films were rinsed with distilled water and ethanol and dried overnight. Finally, the obtained films were annealed in air at $550{ }^{\circ} \mathrm{C}$ for $2 \mathrm{~h}$ and $750{ }^{\circ} \mathrm{C}$ for 30 minutes with a ramping rate of $3{ }^{\circ} \mathrm{C} \mathrm{min}{ }^{-1}$, and red thin films of the ATO IO/ $\mathrm{Fe}_{2} \mathrm{O}_{3}$ composite structure were obtained. ${ }^{40}$ Using colloidal crystals assembled from PS spheres with diameters of 220, 330, and $670 \mathrm{~nm}$, we prepared ATO $\mathrm{IO} / \mathrm{Fe}_{2} \mathrm{O}_{3}$ samples with pore sizes of 220, 330, and $670 \mathrm{~nm}$. The samples were denoted as ATO $\mathrm{IO}(220) / \mathrm{Fe}_{2} \mathrm{O}_{3}$, ATO $\mathrm{IO}(330) / \mathrm{Fe}_{2} \mathrm{O}_{3}$, and ATO $\mathrm{IO}(670) / \mathrm{Fe}_{2} \mathrm{O}_{3}$, respectively. To investigate the advantages of the ATO $\mathrm{IO} / \mathrm{Fe}_{2} \mathrm{O}_{3}$ structures for their PEC properties, a planar control sample was prepared with a similar fabricating process using FTO substrate without colloidal crystal templates. The obtained control sample was designated as planar $\mathrm{ATO} / \mathrm{Fe}_{2} \mathrm{O}_{3}$.

For Sn-doping, the manufacturing process was the same as for the undoped sample at first. After the fabrication of ATO IO and the following hydrothermal reaction, the ATO IO(330)/ FeOOH film was obtained. Then, the film was dipped in $20 \mathrm{mM} \mathrm{SnCl}_{4}$-ethanol solution for 10 minutes to allow $\mathrm{Sn}^{4+}$ to absorb on the surfaces of the FeOOH nanoparticles. Then, the ATO IO(330)/FeOOH samples were annealed in air at $550{ }^{\circ} \mathrm{C}$ for $2 \mathrm{~h}$ and $750{ }^{\circ} \mathrm{C}$ for 30 minutes with a ramping rate of $3^{\circ} \mathrm{C} \mathrm{min}^{-1}$, as with the undoped samples. The as-prepared structure was denoted as Sn-doped ATO $\mathrm{IO} / \mathrm{Fe}_{2} \mathrm{O}_{3}$. 

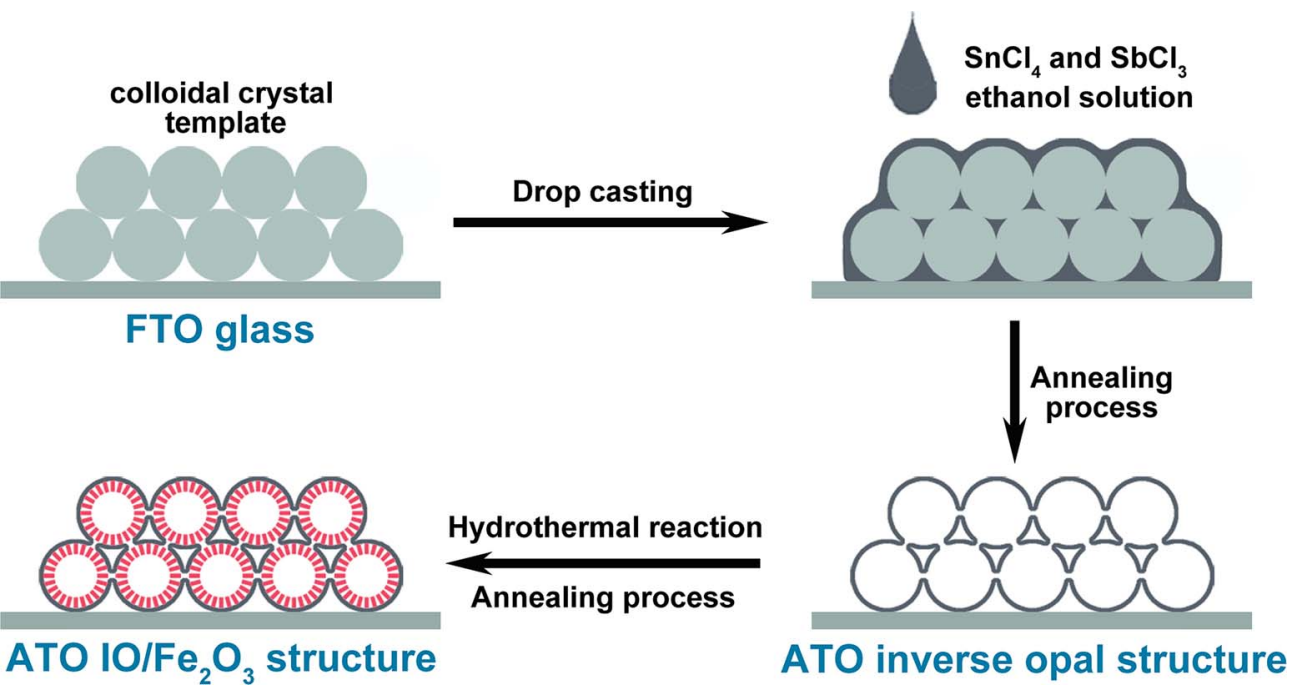

Scheme 1 Schematic of the fabrication process of the ATO $10 / \mathrm{Fe}_{2} \mathrm{O}_{3}$ structures.

\section{Characterization}

The samples were characterized by field-emission scanning electron microscopy (FE-SEM, Hitachi SU8010), transmission electron microscopy (TEM), high-resolution TEM (HRTEM, JEM-200CX) equipped with energy-dispersive X-ray spectroscopy (EDS), powder X-ray diffraction (XRD, Bruker $\mathrm{D} 8, \mathrm{Cu} \mathrm{K} \alpha$ radiation), UV-vis spectroscopy (UV-2450, Shimadzu), and X-ray photoelectron spectroscopy (XPS, Escalab 250Xi).

\section{Photoelectrochemical measurements}

All photoelectrochemical measurements were performed using an Autolab potentiostat in a three-electrode electrochemical cell with a platinum coil as the counter electrode and $\mathrm{Hg} / \mathrm{HgO}$ as the reference electrode. The electrolyte was $1 \mathrm{M} \mathrm{NaOH}(\mathrm{pH} 13.6)$ aqueous solution. The samples were covered with nonconductive epoxy resin to obtain a working area of $0.25 \mathrm{~cm}^{2}$. Linear sweep voltammograms (LSVs) were measured under dark or one-sun conditions (Xe lamp, $100 \mathrm{~mW} \mathrm{~cm}^{-2}$, AM 1.5G) with a sweep rate of $10 \mathrm{mV} \mathrm{s}^{-1}$. The values of the potentials relative to the reversible hydrogen electrode (RHE) were calculated by the Nernst equation:

$$
V_{\mathrm{RHE}}=V_{\mathrm{Hg} / \mathrm{HgO}}+V_{\mathrm{Hg} / \mathrm{HgO}}^{0}+0.059 \mathrm{pH}
$$

where $V_{\mathrm{RHE}}$ is the converted potential $v s$. RHE, $V_{\mathrm{Hg} / \mathrm{HgO}}^{0}=0.098 \mathrm{~V}$ at $25{ }^{\circ} \mathrm{C}$, and $V_{\mathrm{Hg} / \mathrm{HgO}}$ is the measured potential against the $\mathrm{Hg}$ / $\mathrm{HgO}$ reference.

The electrochemical impedance spectra (EIS) were recorded using a CHI660C workstation (CH Instrument, Inc.) under illumination at an applied potential of $1.23 \mathrm{~V} v s$. RHE in the frequency range from $1 \mathrm{MHz}$ to $0.01 \mathrm{~Hz}$. Mott-Schottky measurements were performed in $1 \mathrm{M} \mathrm{NaOH}$ under dark conditions with a frequency of $1 \mathrm{kHz}$. The incident photon-tocurrent conversion efficiency (IPCE) was measured with a bias of $1.23 \mathrm{~V} v s$. RHE using a specially designed IPCE system.

\section{Results and discussion}

Fig. 1 shows typical SEM images of the as-prepared ATO IO and ATO IO/ $\mathrm{Fe}_{2} \mathrm{O}_{3}$ structures. Fig. 1a shows the top view of the ATO IO fabricated from periodic colloidal crystal templates using PSs $330 \mathrm{~nm}$ in diameter. Because of the shrinkage of the ATO IOs during the fabricating process, the diameters of the macropores of the as-fabricated ATO IO are around $280 \mathrm{~nm}$. There are also pores between neighboring macropores with diameters of about 50 to $60 \mathrm{~nm}$, which improves the infiltration of $\mathrm{FeCl}_{3}$ precursor solution into the IO structure. ${ }^{41}$ Then, after the hydrothermal reaction in $\mathrm{FeCl}_{3}$ precursor solution at $120{ }^{\circ} \mathrm{C}$ and calcination at $550{ }^{\circ} \mathrm{C}$, a layer of $\mathrm{Fe}_{2} \mathrm{O}_{3}$ film was evenly grown on the surface of the ATO IO; the well-ordered face-centered cubic arrangement was retained, as shown in Fig. 1b. From Fig. 1c, it can be seen that the $\mathrm{Fe}_{2} \mathrm{O}_{3}$ film is composed of $\mathrm{Fe}_{2} \mathrm{O}_{3}$ nanorods growing radially from the ATO surface. The thickness of the $\mathrm{Fe}_{2} \mathrm{O}_{3}$ film is around 50 to $60 \mathrm{~nm}$, and the pore diameter of the IO structure is about $160 \mathrm{~nm}$. From the cross sectional image (Fig. 1d), it can be seen that the thickness of the $\mathrm{Fe}_{2} \mathrm{O}_{3} / \mathrm{ATO}$ structure is around 8 to $9 \mu \mathrm{m}$.

By using PS spheres with different diameters to assemble the colloidal crystal templates, the pore diameters and, thus, the periodicities of the ATO $\mathrm{IO} / \mathrm{Fe}_{2} \mathrm{O}_{3}$ structures can be readily adjusted. As shown in Fig. 1e and f, ATO $\mathrm{IO}(220) / \mathrm{Fe}_{2} \mathrm{O}_{3}$ and ATO $\mathrm{IO}(670) / \mathrm{Fe}_{2} \mathrm{O}_{3}$ structures could be obtained by using PS spheres with diameters of $220 \mathrm{~nm}$ and $670 \mathrm{~nm}$, respectively. The thicknesses of the $\mathrm{Fe}_{2} \mathrm{O}_{3}$ films in both structures are around $50 \mathrm{~nm}$, which is the same as that of ATO $\mathrm{IO}(330) / \mathrm{Fe}_{2} \mathrm{O}_{3}$. This may be because the same fabricating conditions were used for the $\mathrm{Fe}_{2} \mathrm{O}_{3}$ films in these three structures. In addition, as the diameters of PS spheres decreased from $670 \mathrm{~nm}$ to $220 \mathrm{~nm}$, the pore diameters of the IO structures steadily decreased. Accordingly, the pore diameters of ATO $\mathrm{IO}(220) / \mathrm{Fe}_{2} \mathrm{O}_{3}$ decreased to less than $100 \mathrm{~nm}$, which may be unfavorable for electrolyte infiltration during PEC tests.

To further confirm the core/shell structure of the ATO IO/ $\mathrm{Fe}_{2} \mathrm{O}_{3}$ structures, TEM images of the ATO IO(330)/ $\mathrm{Fe}_{2} \mathrm{O}_{3}$ sample 

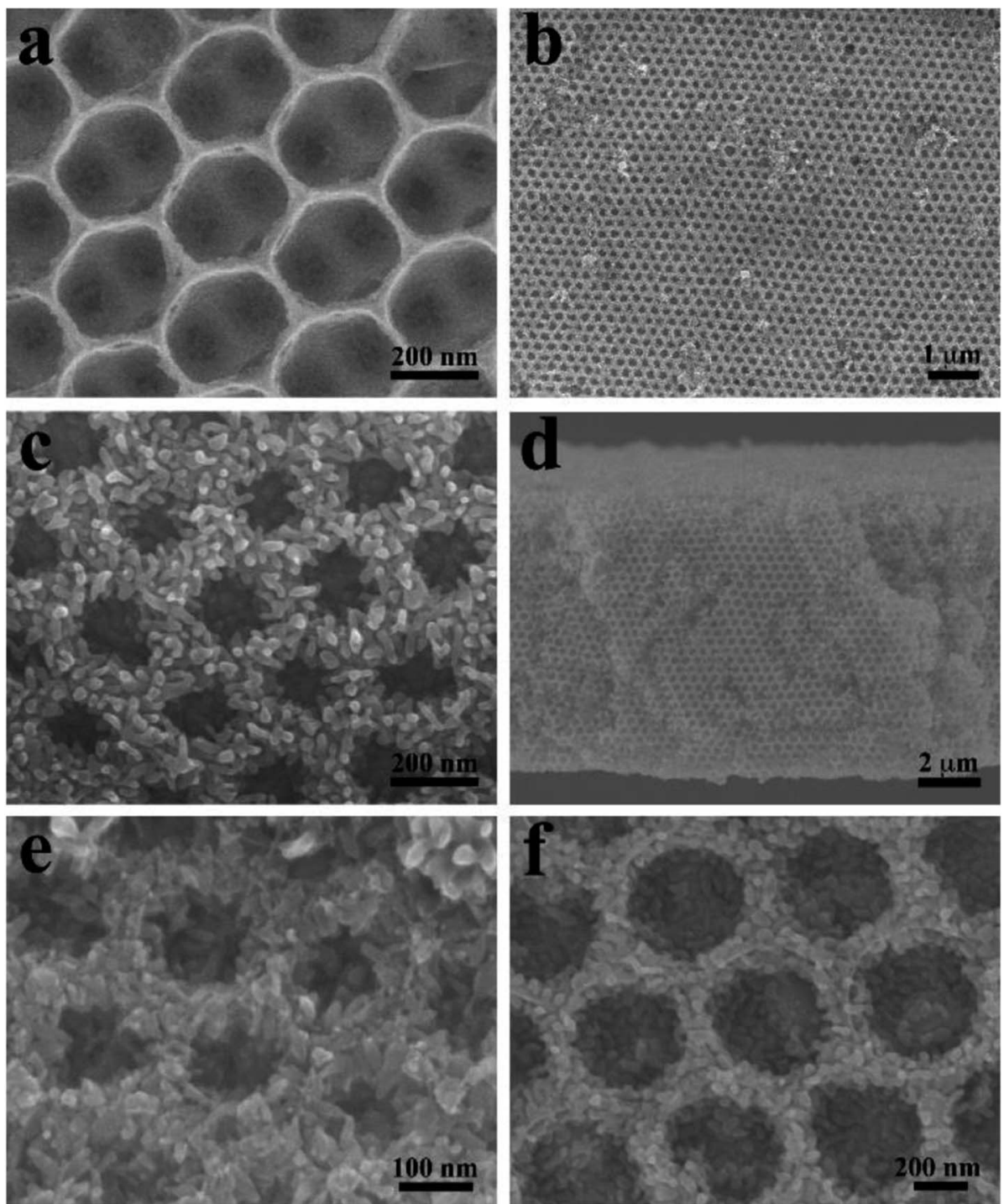

Fig. 1 FE-SEM images of (a) $330 \mathrm{~nm}$ ATO IO; (b and c) top views and (d) cross section view of ATO IO(330)/ $/ \mathrm{Fe}_{2} \mathrm{O}_{3}$, (e) ATO IO(220)/ $\mathrm{Fe} \mathrm{O}_{2}$ film and (f) ATO $\mathrm{IO}(670) / \mathrm{Fe}_{2} \mathrm{O}_{3}$ film.

were acquired, as shown in Fig. 2. The low-resolution view (Fig. 2a) confirms that $\mathrm{Fe}_{2} \mathrm{O}_{3}$ nanorods are tightly coated on the ATO IO skeleton and form a layer of $\mathrm{Fe}_{2} \mathrm{O}_{3}$ film. The thickness of the $\mathrm{Fe}_{2} \mathrm{O}_{3}$ film is roughly 55 to $60 \mathrm{~nm}$, in accordance with the SEM images. Fig. 2b shows a high resolution TEM image of the $\mathrm{Fe}_{2} \mathrm{O}_{3}$ nanorods, which verifies that the as-prepared $\mathrm{Fe}_{2} \mathrm{O}_{3}$ nanorods adopt hematite phase with an interplanar lattice spacing of $0.25 \mathrm{~nm}$ from the (110) plane.

Furthermore, the compositions and elemental distributions of the ATO $\mathrm{IO} / \mathrm{Fe}_{2} \mathrm{O}_{3}$ structures were checked by STEM-EDS element mapping, as shown in Fig. 2c. The $\mathrm{Sn}$ and $\mathrm{Sb}$ elements are homogeneously distributed on the inverse opal skeleton region, which indicates that Sb element was uniformly inserted in the $\mathrm{SnO}_{2}$ lattice and formed ATO. However, Fe element was located around the surface regions of the ATO IOs. This phenomenon confirmed that $\mathrm{Fe}_{2} \mathrm{O}_{3}$ was distributed on the surfaces of the ATO IOs.
To confirm the crystal structures and crystallinities of the asprepared ATO $\mathrm{IO} / \mathrm{Fe}_{2} \mathrm{O}_{3}$ structures, X-ray diffraction (XRD) patterns of the ATO IO and ATO IO(330)/ $\mathrm{Fe}_{2} \mathrm{O}_{3}$ samples were acquired and are shown in Fig. 3a. For the ATO IO sample, all the diffraction peaks match well with $\mathrm{SnO}_{2}$ cassiterite phase (JCPDS no. 41-1445) without any impurity diffraction peaks, which indicates that $\mathrm{Sb}$ acts as a dopant in the $\mathrm{SnO}_{2}$ lattice. The relatively broad peaks of these two samples indicate the presence of small crystallites in the ATO IO structure. For ATO $\mathrm{IO}(330) / \mathrm{Fe}_{2} \mathrm{O}_{3}$, in addition to the diffraction peaks of ATO, the characteristic diffraction peaks of (012), (104), (110), (113), (024), (116), (214), and (300) can be indexed to pure hematite phase (JCPDS no. 33-0664).

The composition of the ATO $\mathrm{IO} / \mathrm{Fe}_{2} \mathrm{O}_{3}$ sample was further characterized by X-ray photoelectron spectroscopy (XPS). According to the survey spectra shown in Fig. 3b, Fe 2p, Sb 3d, $\mathrm{Sn} 3 \mathrm{~d}$ and $\mathrm{O} 1 \mathrm{~s}$ were detected in the sample. The $\mathrm{Sb} 3 \mathrm{~d}$ peak may 

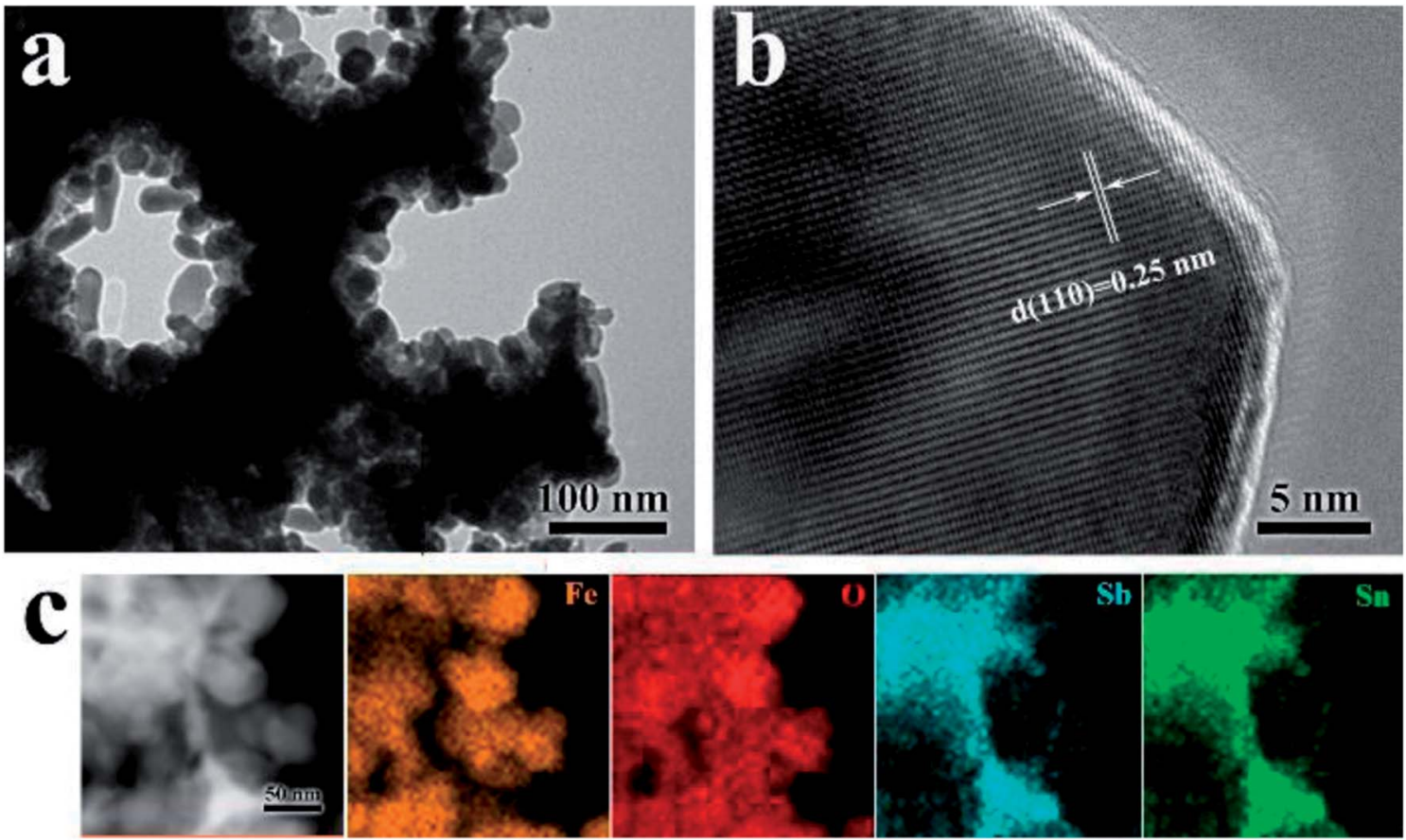

Fig. 2 ( $a$ and b) HRTEM images and (c) STEM image with element mappings of the ATO $1 O(330) / \mathrm{Fe}_{2} \mathrm{O}_{3}$ sample.
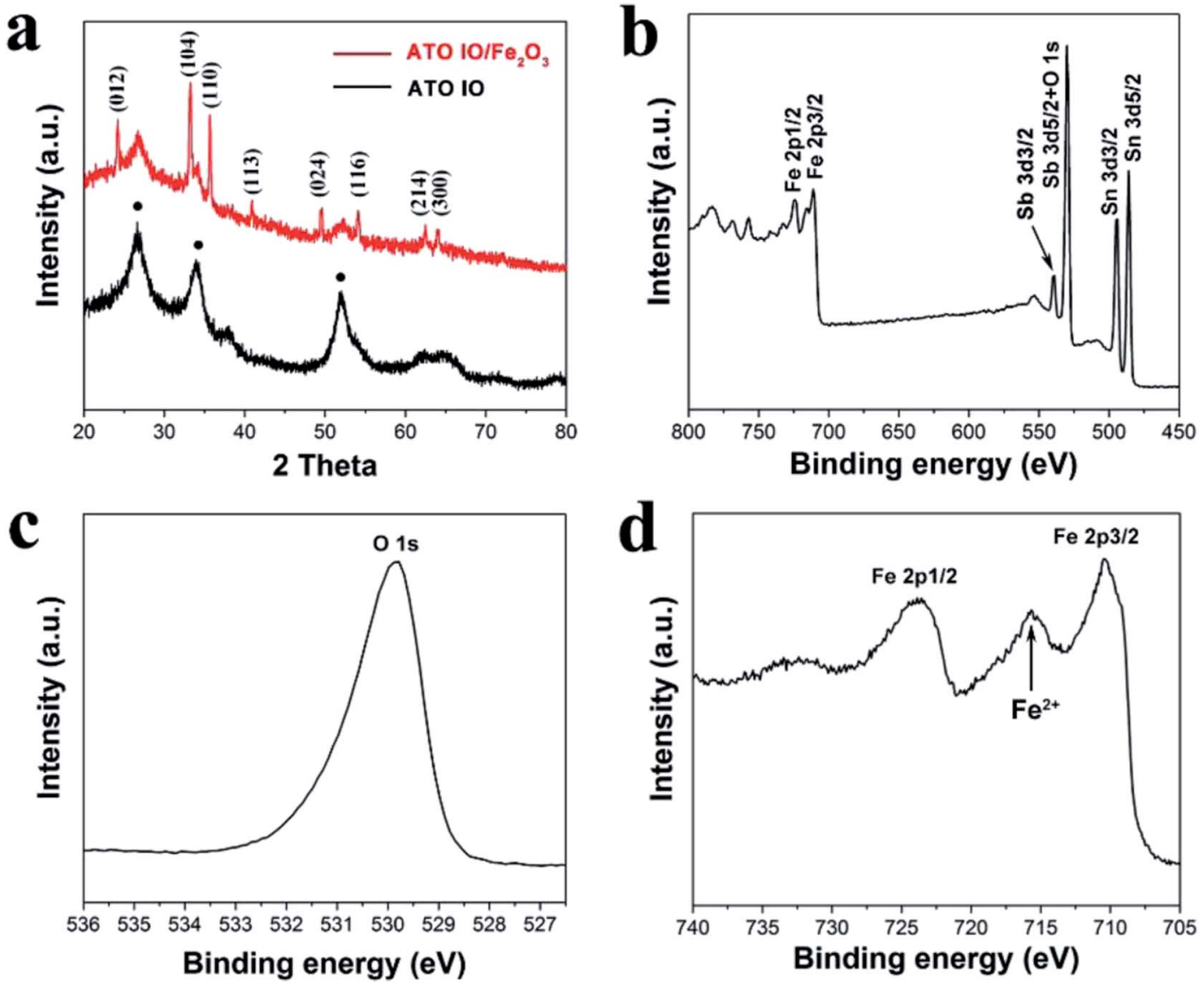

Fig. 3 (a) XRD patterns of the ATO $\mathrm{IO}(330) / \mathrm{Fe}_{2} \mathrm{O}_{3}$ and ATO IO samples (• represents the diffraction peaks of ATO). XPS spectra of (b) survey, high resolution $\mathrm{O}$ 1s (c) and $\mathrm{Fe} 2 \mathrm{p}$ (d) scans for the $\mathrm{ATO} 1 \mathrm{O}(330) / \mathrm{Fe}_{2} \mathrm{O}_{3}$ sample. 
mainly arise due to the incorporation of dopant ions from the ATO inverse opals. The peak at $529.8 \mathrm{eV}$ in the high-resolution spectrum in Fig. $3 \mathrm{c}$ was assigned to the $\mathrm{O}^{2-}$ ions in $\mathrm{Fe}_{2} \mathrm{O}_{3}$. The sample showed two characteristic Fe $2 \mathrm{p}$ bands, as shown in Fig. 3d, which were located at $\sim 724 \mathrm{eV}\left(\mathrm{Fe} 2 \mathrm{p}_{1 / 2}\right)$ and $\sim 710 \mathrm{eV}$ (Fe $2 \mathrm{p}_{3 / 2}$ ), respectively. It is worth noting that there was a $\mathrm{Fe}$ (II) band located at $\sim 716 \mathrm{eV}$, which suggests that high-valent $\mathrm{Sn}$ (Iv) ions substituted and/or occupied vacant interstitial sites and reduced $\mathrm{Fe}^{3+}$ to $\mathrm{Fe}^{2+}$ to maintain overall charge neutrality. This indicates that some Sn(Iv) ions from ATO IO may have been doped into the $\mathrm{Fe}_{2} \mathrm{O}_{3}$ lattice through thermal diffusion. ${ }^{42}$

The photoelectrochemical (PEC) properties of the ATO IO/ $\mathrm{Fe}_{2} \mathrm{O}_{3}$ electrodes with different diameters were studied both in the dark and under simulated AM $1.5 \mathrm{G}$ illumination $(100 \mathrm{~mW}$ $\mathrm{cm}^{-2}$ ) in $1 \mathrm{M} \mathrm{NaOH}$ electrolyte $(\mathrm{pH}=13.6)$. For comparison, a planar $\mathrm{ATO} / \mathrm{Fe}_{2} \mathrm{O}_{3}$ photoanode was fabricated by a similar process without IO templates. As shown in the resulting linear sweep voltammograms (LSVs) in Fig. 4a, as the applied positive potential increased, the photocurrents increased steadily under illumination, while the dark currents were negligible. It is clear that the ATO $\mathrm{IO} / \mathrm{Fe}_{2} \mathrm{O}_{3}$ electrodes showed better performance than the planar sample over the potential range from 0.6 to $1.7 \mathrm{~V} v s$. RHE. At $1.23 \mathrm{~V} v s$. RHE, the photocurrent densities of the ATO IO(220)/ $/ \mathrm{Fe}_{2} \mathrm{O}_{3}$, ATO $\mathrm{IO}(330) / \mathrm{Fe}_{2} \mathrm{O}_{3}$, and ATO $\mathrm{IO}(670) /$ $\mathrm{Fe}_{2} \mathrm{O}_{3}$ photoanodes were $0.88 \mathrm{~mA} \mathrm{~cm}{ }^{-2}, 1.04 \mathrm{~mA} \mathrm{~cm}^{-2}$, and 0.69 $\mathrm{mA} \mathrm{cm} \mathrm{cm}^{-2}$, which are 7 times, 8 times and 5 times higher than that of the planar $\mathrm{ATO} / \mathrm{Fe}_{2} \mathrm{O}_{3}$ electrode $\left(0.13 \mathrm{~mA} \mathrm{~cm} \mathrm{~cm}^{-2}\right)$, respectively. The enhanced PEC performance of the ATO IO/ $\mathrm{Fe}_{2} \mathrm{O}_{3}$ photoanode compared to the planar control can be attributed to the following reasons. Firstly, the inverse opal structure has periodically arranged macropores that connect very well with each other, which allows efficient charge transport to the conducting substrates and electrolyte. Another benefit is the enhanced light trapping effect due to the multipass scattering of incident light originating from the $3 \mathrm{D}$ periodical structures, which will be discussed later.

It is worth mentioning that the photocurrent densities of the three inverse opal electrodes with different diameters are different. Firstly, the photocurrent density of ATO $\mathrm{IO}(220) / \mathrm{Fe}_{2} \mathrm{O}_{3}$ is lower than that of the ATO $\mathrm{IO}(330) / \mathrm{Fe}_{2} \mathrm{O}_{3}$ photoanode over the tested potential range. This may be due to the smaller pore sizes of the ATO $\mathrm{IO}(220) / \mathrm{Fe}_{2} \mathrm{O}_{3}$ sample, which leads to smaller and fewer voids inside the IO structure; this may be unfavorable for mass infiltration and transfer inside the photoanode. ${ }^{33}$ On the other hand, the photocurrent density of ATO $\mathrm{IO}(670) / \mathrm{Fe}_{2} \mathrm{O}_{3}$ is the lowest among the three ATO $\mathrm{IO} / \mathrm{Fe}_{2} \mathrm{O}_{3}$ samples, which may be due to its less enhanced light absorption, as discussed later.

To investigate and understand the improved PEC performance of the ATO $\mathrm{IO} / \mathrm{Fe}_{2} \mathrm{O}_{3}$ structures, UV-vis absorption spectra of the ATO IO/ $\mathrm{Fe}_{2} \mathrm{O}_{3}$ samples with different diameters as well as the planar $\mathrm{ATO} / \mathrm{Fe}_{2} \mathrm{O}_{3}$ sample were measured and are shown in Fig. 4b. Firstly, it is unfortunate that the as-prepared ATO IO/ $\mathrm{Fe}_{2} \mathrm{O}_{3}$ samples did not show specific absorption peaks at the photonic bandgaps, which may be due to the rough $\mathrm{Fe}_{2} \mathrm{O}_{3}$
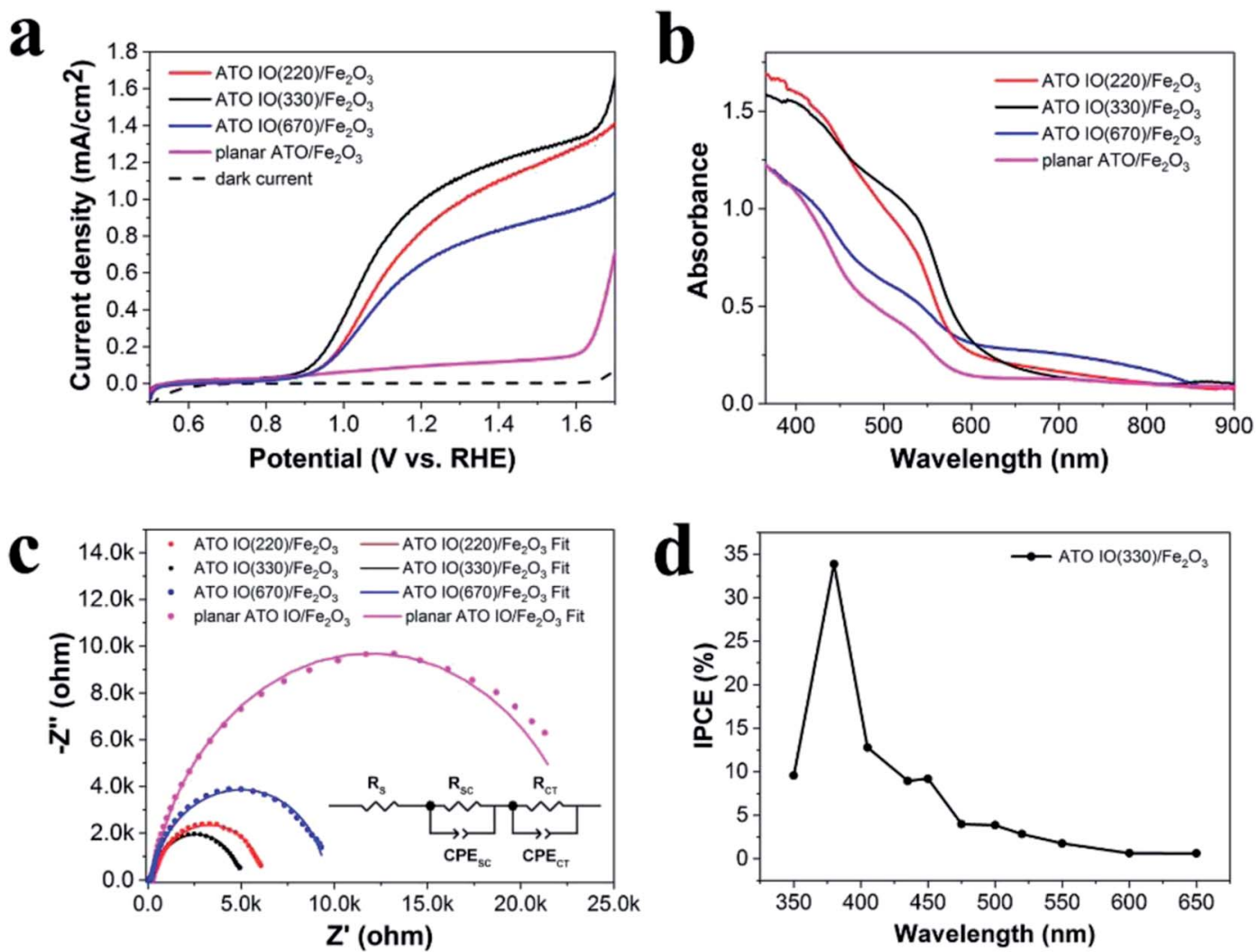

Fig. 4 Linear sweep voltammograms (a), UV-vis absorption spectra (b) and EIS Nyquist plots (c) of ATO IO/Fe $\mathrm{O}_{3}$ with different diameters and a planar control sample. (d) Incident photon-to-current efficiency (IPCE) spectrum of the ATO IO(330)/ $\mathrm{Fe}_{2} \mathrm{O}_{3}$ sample. 
layer inside ATO IO structure and the polycrystalline nature of the IO structure. However, the three ATO IO/ $/ \mathrm{Fe}_{2} \mathrm{O}_{3}$ samples still exhibited strong and broad absorption enhancement compared to the planar control. This absorption enhancement of the ATO $\mathrm{IO} / \mathrm{Fe}_{2} \mathrm{O}_{3}$ samples can be attributed to the multi-pass scattering of incident light obtained due to the larger dimensions of the IO structures compared to the planar film. ${ }^{42}$ On the other hand, the roughness of the $\mathrm{Fe}_{2} \mathrm{O}_{3}$ nanoparticle layer inside the ATO IO structure can further benefit the multi-scattering of incident light and hence allow more light to be trapped inside the nanostructure samples. As a result, the ATO $\mathrm{IO} / \mathrm{Fe}_{2} \mathrm{O}_{3}$ samples with diameters of $220 \mathrm{~nm}$ and $330 \mathrm{~nm}$ exhibited significant absorption enhancement compared to the planar films, especially in the wavelength range of 370 to $700 \mathrm{~nm}$. However, for the ATO $\mathrm{IO}(670) / \mathrm{Fe}_{2} \mathrm{O}_{3}$ sample, the light absorption was only slightly enhanced, and the enhancement was mainly in the region of 700 to $800 \mathrm{~nm}$. Because the electronic absorption edge of $\mathrm{Fe}_{2} \mathrm{O}_{3}$ is $2.1 \mathrm{eV}$, it can absorb light with wavelengths below $590 \mathrm{~nm} .{ }^{43}$ Hence, the PEC performance of ATO $\mathrm{IO}(670) / \mathrm{Fe}_{2} \mathrm{O}_{3}$ was not as enhanced as that of the ATO $\mathrm{IO}(330) / \mathrm{Fe}_{2} \mathrm{O}_{3}$ sample. This is likely due to the inefficient light scattering effect and decreased surface area caused by the larger nanostructures. Therefore, the optimized diameter of the ATO IO/ $/ \mathrm{Fe}_{2} \mathrm{O}_{3}$ sample is $330 \mathrm{~nm}$, which allows excellent light scattering effects while retaining efficient charge transport, leading to the most enhanced PEC performance.

Electrochemical impedance spectroscopy (EIS) was employed to further investigate the promoting effects of the IO structure on the PEC properties, and the Nyquist plots were measured under illumination of AM 1.5G light, $100 \mathrm{~mW} \mathrm{~cm} \mathrm{~cm}^{-2}$, at a bias of $1.23 \mathrm{~V} v s$. RHE. Fig. 4c shows typical Nyquist plots and fitted results of the ATO $\mathrm{IO} / \mathrm{Fe}_{2} \mathrm{O}_{3}$ structures with different diameters and the planar control sample. The experimental data fitted well with the equivalent circuits shown in the inset, where $R_{\mathrm{S}}$ is the ohmic contribution, $R_{\mathrm{SC}}$ at high frequency region indicates the charge-transfer resistance at the counter electrode/electrolyte interface, ${ }^{44} R_{\mathrm{CT}}$ in the low frequency region correlates with the semiconductor/electrolyte charge transfer resistance, and $\mathrm{CPE}_{\mathrm{SC}}$ and $\mathrm{CPE}_{\mathrm{CT}}$ represent the corresponding constant phase elements of the device, respectively. ${ }^{5}$ The fitted values of the different resistances are shown in Table 1 . The Nyquist plots contained two arcs for all the samples, and the large arcs in the low frequency region correspond to the chargerecombination resistance at the $\mathrm{Fe}_{2} \mathrm{O}_{3}$ /electrolyte interface. It is obvious that the ATO IO/ $/ \mathrm{Fe}_{2} \mathrm{O}_{3}$ samples had much smaller $R_{\mathrm{SC}}$ and $R_{\mathrm{CT}}$ values than the planar control, which confirms that both the $R_{\mathrm{SC}}$ and $R_{\mathrm{CT}}$ values can be decreased by the

Table 1 Quantitative values of ohmic resistance $\left(R_{\mathrm{S}}\right)$ and chargetransfer resistance $\left(R_{\mathrm{SC}}\right.$ and $\left.R_{\mathrm{CT}}\right)$ of the ATO $1 \mathrm{O} / \mathrm{Fe}_{2} \mathrm{O}_{3}$ films with different diameters and the planar $\mathrm{ATO} / \mathrm{Fe}_{2} \mathrm{O}_{3}$ control sample

\begin{tabular}{lccl}
\hline & $R_{\mathrm{S}}(\Omega)$ & $R_{\mathrm{SC}}(\Omega)$ & $R_{\mathrm{CT}}(\Omega)$ \\
\hline ATO IO $(220) / \mathrm{Fe}_{2} \mathrm{O}_{3}$ & 12.43 & 88.69 & 6191 \\
ATO IO $(330) / \mathrm{Fe}_{2} \mathrm{O}_{3}$ & 11.36 & 89.74 & 4907 \\
ATO IO $(670) / \mathrm{Fe}_{2} \mathrm{O}_{3}$ & 10.56 & 87.44 & 9481 \\
Planar ATO $/ \mathrm{Fe}_{2} \mathrm{O}_{3}$ & 20.33 & 228.5 & 23390
\end{tabular}

introduction of IO structures. Moreover, the $R_{\mathrm{CT}}$ values of ATO $\mathrm{IO} / \mathrm{Fe}_{2} \mathrm{O}_{3}$ with different diameters were different; the $R_{\mathrm{CT}}$ value of the ATO $\mathrm{IO}(330) / \mathrm{Fe}_{2} \mathrm{O}_{3}$ film was the lowest, followed by those of ATO $\mathrm{IO}(220) / \mathrm{Fe}_{2} \mathrm{O}_{3}$ and ATO $\mathrm{IO}(670) / \mathrm{Fe}_{2} \mathrm{O}_{3}$ in the stated sequence, which is consistent with the $J-V$ curves. This confirms that the ATO $\mathrm{IO} / \mathrm{Fe}_{2} \mathrm{O}_{3}$ samples with suitable diameters show improved conductivity and decreased bulk recombination. This result further explains the enhanced PEC performance of the ATO $\mathrm{IO}(330) / \mathrm{Fe}_{2} \mathrm{O}_{3}$ samples.

Incident photo-to-current conversion efficiency (IPCE) measurements were carried out on ATO IO $(330) / \mathrm{Fe}_{2} \mathrm{O}_{3}$ at $1.23 \mathrm{~V}$ vs. RHE. The IPCE was calculated from eqn (2):

$$
\mathrm{IPCE}=(1240 I) /\left(\lambda J_{\text {light }}\right)
$$

where $I$ is the photocurrent density, $J_{\text {light }}$ is the incident light density and $\lambda$ is the wavelength of incident monochromatic light. ${ }^{31}$ As shown in Fig. 4d, the sample showed enhanced photoactivity in the range of 350 to $500 \mathrm{~nm}$, which is consistent with the absorption spectroscopy results. At $380 \mathrm{~nm}$, the IPCE was as high as $34 \%$, which was attributed to suppressed charge recombination and enhanced light absorption through the structure of ATO $\mathrm{IO} / \mathrm{Fe}_{2} \mathrm{O}_{3}$.

Previous studies revealed that the photoelectrochemical performance of hematite can be effectively enhanced by doping with high valent ions, such as $\mathrm{Sn}^{4+}$ and $\mathrm{Ti}^{4+}$. Herein, to further enhance the PEC activity of ATO IO/ $\mathrm{Fe}_{2} \mathrm{O}_{3}$, a Sn-doped ATO IO/ $\mathrm{Fe}_{2} \mathrm{O}_{3}$ film was prepared by following the same experimental procedure except that ATO $\mathrm{IO} / \mathrm{FeOOH}$ was immersed in $\mathrm{SnCl}_{4}-$ ethanol solution before annealing. Fig. 5a shows the top FESEM images of the Sn-doped ATO $\mathrm{IO}(330) / \mathrm{Fe}_{2} \mathrm{O}_{3}$ film. The IO structure of the sample was well arranged and the $\mathrm{Fe}_{2} \mathrm{O}_{3}$ nanoparticles were evenly covered on the ATO IO wall. The morphology of the Sn-doped ATO $\mathrm{IO} / \mathrm{Fe}_{2} \mathrm{O}_{3}$ film was almost identical to that of the undoped ATO $\mathrm{IO} / \mathrm{Fe}_{2} \mathrm{O}_{3}$ structure, which indicates that Sn-doping did not affect the morphology of the as-prepared ATO IO/ $\mathrm{Fe}_{2} \mathrm{O}_{3}$ structure. To investigate the crystal structure and possible phase changes of the sample during Sndoping, the Sn-doped ATO IO/ $\mathrm{Fe}_{2} \mathrm{O}_{3}$ sample was examined by Xray diffraction, and the spectrum was compared with that of the undoped sample, as shown in Fig. 5b. The spectra of both samples were quite similar; they exhibited typical polycrystalline rutile $\mathrm{SnO}_{2}$ phase (JCPDS no. 41-1445) and hematite phase (JCPDS no. 33-0664). The diffraction peaks of hematite in the doped sample showed no observable shifts compared to the undoped sample, suggesting that the main crystal structure of hematite was not affected during doping.

In order to investigate the composition of the sample after Sn-doping, XPS measurements of the Sn-doped ATO IO/ $/ \mathrm{Fe}_{2} \mathrm{O}_{3}$ sample were conducted; the high resolution $\mathrm{O}$ 1s spectra and $\mathrm{Sn}$ $3 \mathrm{~d}$ spectra of the Sn-doped and undoped samples are shown in Fig. $5 \mathrm{c}$ and d, respectively. As shown in Fig. $5 \mathrm{c}$, the peak of $\mathrm{O} 1 \mathrm{~s}$ at a binding energy of $\approx 530.0 \mathrm{eV}$ of the Sn-doped ATO IO/ $/ \mathrm{Fe}_{2} \mathrm{O}_{3}$ sample showed a slight red shift compared to that of the undoped sample $(\approx 529.8 \mathrm{eV}$ ), which is consistent with the lower electron density around $\mathrm{O}$ after Sn-doping. ${ }^{45,46}$ On the other hand, as shown in Fig. 5d, the Sn-doped ATO IO/ $\mathrm{Fe}_{2} \mathrm{O}_{3}$ 

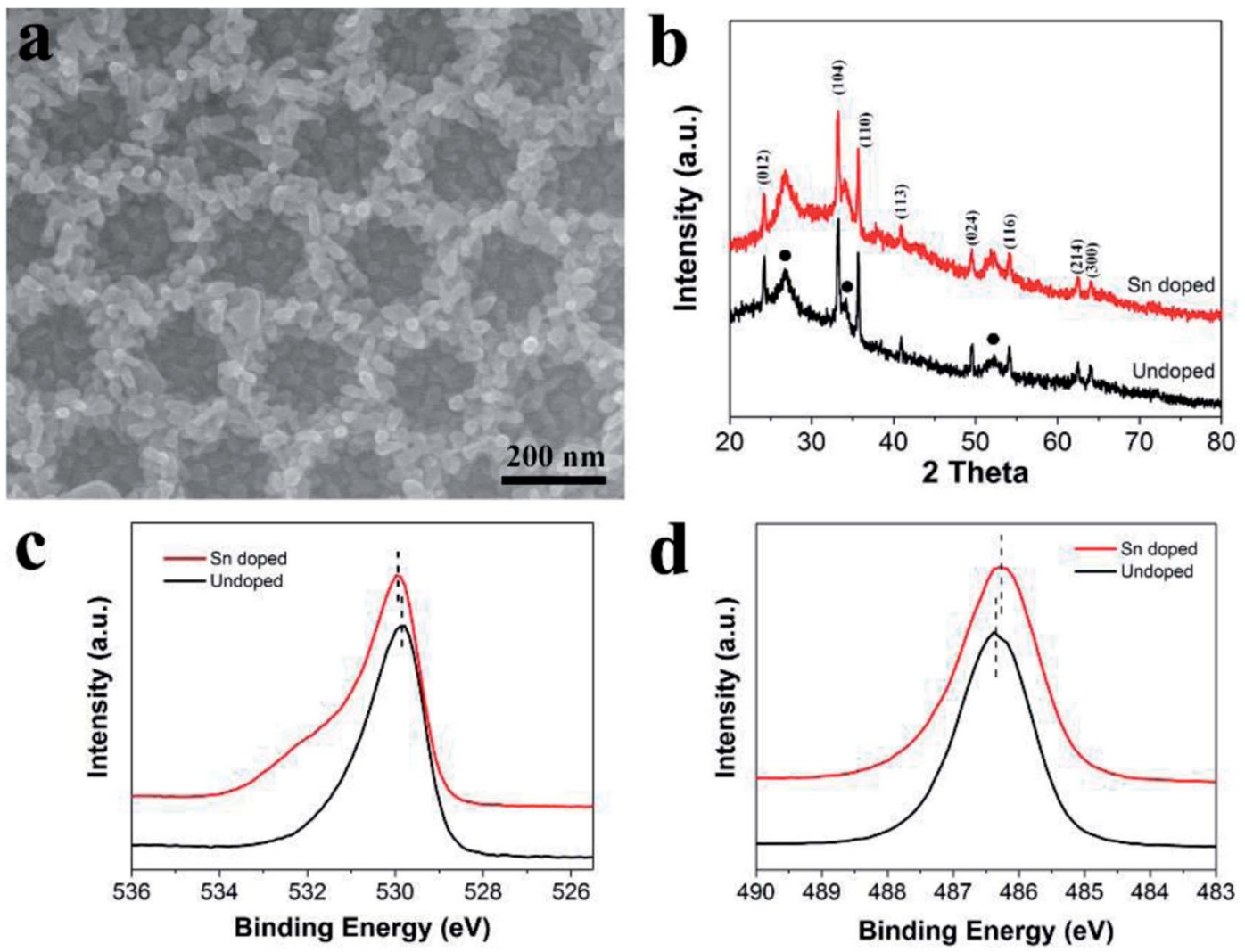

Fig. 5 (a) FE-SEM image of the $\mathrm{Sn}$-doped ATO IO(330)/Fe $\mathrm{O}_{3}$ sample. Comparison of the $\mathrm{Sn}$-doped and undoped $\mathrm{ATO} I \mathrm{O}(330) / \mathrm{Fe} \mathrm{O}_{3}$ samples: (b) XRD patterns (• represents the diffraction peaks of ATO), (c) XPS O 1s bands and (d) XPS Sn 3d bands.

sample showed a lower Sn $3 \mathrm{~d}^{5 / 2}$ peak at a binding energy of around $486.3 \mathrm{eV}$. This blue shift of the binding energy peak can be attributed to the incorporation of Sn into the FeO structure. ${ }^{18}$ Based on the above analysis, Sn ions were successfully doped into the hematite structure, and the Sn-doping process did not affect the morphology of the ATO $\mathrm{IO} / \mathrm{Fe}_{2} \mathrm{O}_{3}$ sample. Fig. S1 in the ESI $\dagger$ shows the diffuse reflectance UV-vis spectra and corresponding Tauc plots of the Sn-doped and undoped ATO $\mathrm{IO}(330) / \mathrm{Fe}_{2} \mathrm{O}_{3}$ samples and the planar control sample. The diffuse reflectance UV-vis spectra shown in Fig. S1a $\dagger$ reveal that the absorbance of the ATO $\mathrm{IO}(330) / \mathrm{Fe}_{2} \mathrm{O}_{3}$ structure was obviously enhanced compared to that of the planar control, which is in accordance with previous results and analysis. In the meantime, Sn-doping showed no obvious influence on the absorbance, which indicates that Sn-doping did not affect the morphology of the ATO $\mathrm{IO} / \mathrm{Fe}_{2} \mathrm{O}_{3}$ structure. The bandgaps obtained from the Tauc plots slightly decreased from $2.06 \mathrm{eV}$ for the planar control sample to $2.05 \mathrm{eV}$ and $2.04 \mathrm{eV}$ for the undoped and Sn-doped ATO $\mathrm{IO}(330) / \mathrm{Fe}_{2} \mathrm{O}_{3}$ samples, respectively (Fig. S1b $\dagger$ ). This slight change in the bandgap implies that the Sn-doping level in our experiment is relatively low and has little influence on the bandgap energy of $\mathrm{Fe}_{2} \mathrm{O}_{3}{ }^{8,18}$

To investigate the photoelectrochemical behavior of the Sndoped ATO IO/ $/ \mathrm{Fe}_{2} \mathrm{O}_{3}$ structure, the LSV of the Sn-doped ATO $\mathrm{IO}(330) / \mathrm{Fe}_{2} \mathrm{O}_{3}$ photoanode was measured under the same experimental conditions as the previous tests and compared with that of the undoped sample, as shown in Fig. 6a. It is obvious that the Sn-doped sample exhibited a significantly enhanced current density of $1.28 \mathrm{~mA} \mathrm{~cm}^{-2}$ at $1.23 \mathrm{~V} v s$. RHE compared to that of the undoped sample $\left(1.04 \mathrm{~mA} \mathrm{~cm}{ }^{-2}\right.$ at $1.23 \mathrm{~V}$ vs. RHE). Approximately $23 \%$ enhancement was achieved by Sn-doping. To probe the PEC enhancement mechanism of Sn-doping, Mott-Schottky plots and EIS measurements of Sndoped ATO $\mathrm{IO}(330) / \mathrm{Fe}_{2} \mathrm{O}_{3}$ sample were examined, as shown in Fig. $6 \mathrm{~b}$ and c.

The Mott-Schottky plots (M-S plots) were employed to investigate the effects of Sn-doping on the electrochemical properties of the ATO $\mathrm{IO} / \mathrm{Fe}_{2} \mathrm{O}_{3}$ sample. As shown in Fig. 6b, the $\mathrm{M}-\mathrm{S}$ plots of the Sn-doped and undoped ATO $\mathrm{IO}(330) / \mathrm{Fe}_{2} \mathrm{O}_{3}$ samples were measured in the dark at a frequency of $1 \mathrm{kHz}$. The positive slopes of the M-S plots indicated that both samples are n-type semiconductors, which is consistent with previous reports. ${ }^{12}$ On the other hand, $\mathrm{M}-\mathrm{S}$ plots can give information about the donor densities by the Mott-Schottky equation:

$$
N_{\mathrm{d}}=\frac{2}{q \varepsilon \varepsilon_{0}}\left[\frac{\mathrm{d}\left(\frac{1}{C^{2}}\right)}{\mathrm{d} V}\right]^{-1}
$$

where $N_{\mathrm{d}}, C, q, \varepsilon_{0}, \varepsilon$, and $V$ are the carrier density, capacitance per unit area, elementary charge, dielectric constant of hematite (80) ${ }^{47}$ permittivity of vacuum, and electrode applied potential, respectively. As a result, the donor densities were calculated to be $3.42 \times 10^{20}$ and $6.30 \times 10^{20} \mathrm{~cm}^{-3}$ for the undoped and $\mathrm{Sn}$ - 

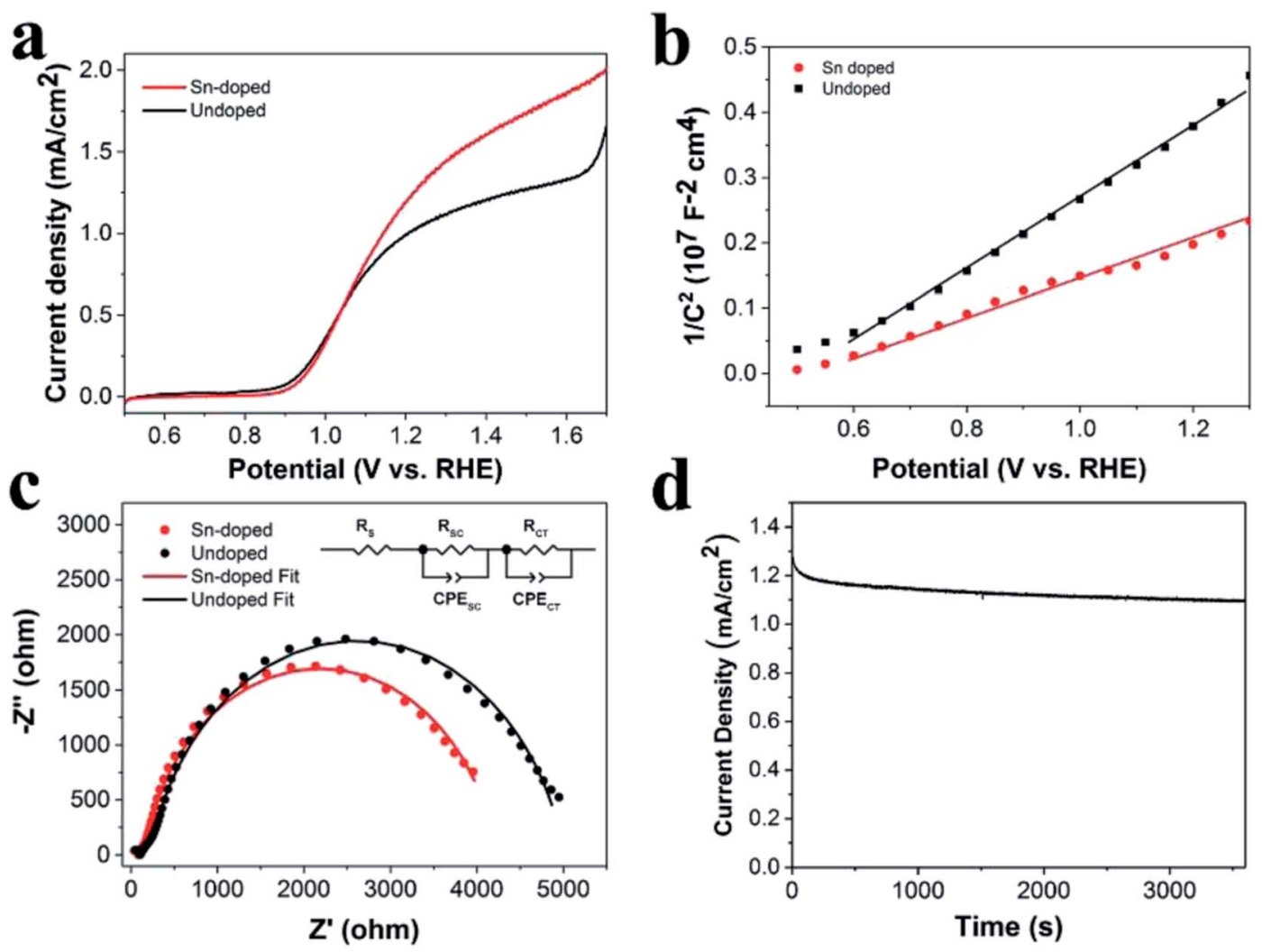

Fig. 6 (a) LSVs, (b) Mott-Schottky plots, and (c) EIS Nyquist plots of the Sn-doped and undoped ATO IO(330)/Fe $2 \mathrm{O}_{3}$ samples. (d) Photocurrent of the $\mathrm{Sn}$-doped ATO $\mathrm{IO}(330) / \mathrm{Fe}_{2} \mathrm{O}_{3}$ photoanode at a potential of $1.23 \mathrm{~V}$ vs. RHE under AM $1.5 \mathrm{G}$ illumination for $3600 \mathrm{~s}$.

doped ATO $\mathrm{IO}(330) / \mathrm{Fe}_{2} \mathrm{O}_{3}$ samples, respectively, which are comparable to previously reported values of Sn-doped and pristine hematite. ${ }^{12}$ Clearly, Sn-doping increased the donor densities of the ATO IO/ $/ \mathrm{Fe}_{2} \mathrm{O}_{3}$ samples; this may be due to the improvement of the conductivity and the resulting faster collection of photogenerated electrons. In addition, the Nyquist plot (Fig. 6c) of the Sn-doped ATO $\mathrm{IO}(330) / \mathrm{Fe}_{2} \mathrm{O}_{3}$ photoanode was measured under the same experimental conditions as the previous plots and was fitted using the equivalent circuit in the inset of Fig. 6c. As a result, the $R_{\mathrm{CT}}$ value $(4100 \Omega)$ of the Sndoped sample decreased relative to that of the undoped sample (4907 $\Omega$ ); this indicated an enhanced charge transfer process at the hematite-electrolyte interface and, hence, suppressed surface recombination. These results provided evidence that the enhanced PEC properties of the Sn-doped sample may be due to the increased donor density and elevated conductivity, which lead to an enhanced charge transfer process and suppressed charge recombination.

In addition, Fig. $6 \mathrm{~d}$ shows the photocurrent density of the Sn-doped ATO IO(330)/ $/ \mathrm{Fe}_{2} \mathrm{O}_{3}$ sample over time at $1.23 \mathrm{~V} v$ s. RHE under AM 1.5G illumination $\left(100 \mathrm{~mW} \mathrm{~cm}^{-2}\right)$ in $1 \mathrm{M} \mathrm{NaOH}$ electrolyte. As a result, the Sn-doped ATO $\mathrm{IO}(330) / \mathrm{Fe}_{2} \mathrm{O}_{3}$ photoanode exhibits only a slight decay in the photocurrent density over $3600 \mathrm{~s}$, which implies that the as-prepared heterostructures are highly stable chemically and optically.

We compared the PEC performance of several $\mathrm{Fe}_{2} \mathrm{O}_{3}$-based nanostructured photoanodes, and the results are listed in Table S1. $\uparrow$ Among the Sn-doped hematite nanostructures and $\mathrm{Fe}_{2} \mathrm{O}_{3} /$ conductive inverse opal heterostructures, the PEC performance of the as-prepared Sn-doped ATO $\mathrm{IO}(330) / \mathrm{Fe}_{2} \mathrm{O}_{3}$ photoanode was superior. The highly conductive ATO IO provides fast charge transfer paths and enhanced light absorbance ability, while Sn-doping enhanced the conductivity of $\mathrm{Fe}_{2} \mathrm{O}_{3}$. The combination of two strategies in our heterostructures resulted in a higher photocurrent than those of similar reported $\mathrm{Fe}_{2} \mathrm{O}_{3^{-}}$ based photoanodes. ${ }^{16,28,31,36,48-50}$ Although the PEC performance of the as-prepared Sn-doped ATO $\mathrm{IO} / \mathrm{Fe}_{2} \mathrm{O}_{3}$ heterostructures is not superior, the utilization of the conductive IO structure, especially the discussion of the influence of the pore sizes of IO structures, provides a novel concept and a basic reference for improvement of the PEC performance of $\mathrm{Fe}_{2} \mathrm{O}_{3}$ and other semiconductors.

\section{Conclusions}

In summary, we have designed and fabricated novel ATO IO/ $\mathrm{Fe}_{2} \mathrm{O}_{3}$ heterostructures using colloidal crystals as templates, and their PEC properties were thoroughly studied. By using colloidal crystal templates with different diameters, we could controllably tune the diameters of the ATO $\mathrm{IO} / \mathrm{Fe}_{2} \mathrm{O}_{3}$ heterostructures. The as-prepared ATO $\mathrm{IO} / \mathrm{Fe}_{2} \mathrm{O}_{3}$ heterostructures exhibit enhanced PEC properties compared to the planar ATO/ $\mathrm{Fe}_{2} \mathrm{O}_{3}$ reference sample. This significant enhancement is ascribed to the high conductivity of the ATO skeleton as well as the high specific area and good light harvesting properties of the $3 \mathrm{D}$ IO structures. In particular, the diameters of the ATO IO 
skeletons could affect the optical and electrical properties of the ATO $\mathrm{IO} / \mathrm{Fe}_{2} \mathrm{O}_{3}$ heterostructures and hence affect their PEC properties. Moreover, the PEC properties of the ATO IO/ $/ \mathrm{Fe}_{2} \mathrm{O}_{3}$ heterostructures could be further enhanced by Sn-doping. Under optimal conditions, the photocurrent density of Sndoped ATO $\mathrm{IO} / \mathrm{Fe}_{2} \mathrm{O}_{3}$ reached $1.28 \mathrm{~mA} \mathrm{~cm}{ }^{-2}$ at $1.23 \mathrm{~V}$ vs. RHE, and the enhancing mechanism of Sn-doping was studied. Overall, our study suggests that the IO skeleton can enhance the PEC properties of photoanodes, and morphology tuning by controlling repetitive periods can further elevate PEC properties via optimizing light harvesting and charge transfer properties. This research and strategy may provide a new route to design and optimize nanostructured photoanodes by morphology tuning and engineering.

\section{Conflicts of interest}

There are no conflicts to declare.

\section{Acknowledgements}

This study was financially supported by the National Natural Science Foundation of China (Grant No. 21503085 and 21603079), the Natural Science Foundation of Hubei Province (Grant No. 2015CFB233 and 2015CFB175), the open funds of the State Key Laboratory of Agricultural Microbiology (Grant No. AMLKF201507), and the Da Bei Nong Group Promoted Project for Young Scholar of HZAU (Grant No. 2017DBN010).

\section{Notes and references}

1 M. Grätzel, Nature, 2001, 414, 338.

2 K. Sivula and R. van de Krol, Nat. Rev. Mater., 2016, 1, 15010.

3 A. Fujishima and K. Honda, Nature, 1972, 238, 37.

4 T. Ling, S. A. Kulinich, Z.-L. Zhu, S.-Z. Qiao and X.-W. Du, Adv. Funct. Mater., 2014, 24, 707-715.

5 G. Yun, M. Balamurugan, H.-S. Kim, K.-S. Ahn and S. H. Kang, J. Phys. Chem. C, 2016, 120, 5906-5915.

6 L. Zhou, C. Zhao, B. Giri, P. Allen, X. Xu, H. Joshi, Y. Fan, L. V. Titova and P. M. Rao, Nano Lett., 2016, 16, 3463-3474.

7 A. B. Murphy, P. R. F. Barnes, L. K. Randeniya, I. C. Plumb, I. E. Grey, M. D. Horne and J. A. Glasscock, Int. J. Hydrogen Energy, 2006, 31, 1999-2017.

8 S. Kment, F. Riboni, S. Pausova, L. Wang, L. Wang, H. Han, Z. Hubicka, J. Krysa, P. Schmuki and R. Zboril, Chem. Soc. Rev., 2017, 46, 3716-3769.

9 K. Sivula, R. Zboril, F. Le Formal, R. Robert, A. Weidenkaff, J. Tucek, J. Frydrych and M. Grätzel, J. Am. Chem. Soc., 2010, 132, 7436-7444.

10 A. G. Tamirat, J. Rick, A. A. Dubale, W.-N. Su and B.-J. Hwang, Nanoscale Horiz., 2016, 1, 243-267.

11 B. Iandolo, B. Wickman, I. Zorić and A. Hellman, J. Mater. Chem. A, 2015, 3, 16896-16912.

12 D.-D. Qin, Y.-L. Li, T. Wang, Y. Li, X.-Q. Lu, J. Gu, Y.-X. Zhao, Y.-M. Song and C.-L. Tao, J. Mater. Chem. A, 2015, 3, 67516755 .
13 A. J. Abel, I. Garcia-Torregrosa, A. M. Patel, B. Opasanont and J. B. Baxter, J. Phys. Chem. C, 2015, 119, 4454-4465.

14 C. Han-Wei, F. Yanming, L. Wan-Yi, L. Ying-Rui, H. YuCheng, C. Jeng-Lung, C. Chi-Liang, C. Wu Ching, C. JinMing, L. Jyh-Fu, S. Shaohua and D. Chung-Li, Nanotechnology, 2018, 29, 064002.

15 A. Annamalai, P. S. Shinde, T. H. Jeon, H. H. Lee, H. G. Kim, W. Choi and J. S. Jang, Sol. Energy Mater. Sol. Cells, 2016, 144, 247-255.

16 M. Li, Y. Yang, Y. Ling, W. Qiu, F. Wang, T. Liu, Y. Song, X. Liu, P. Fang, Y. Tong and Y. Li, Nano Lett., 2017, 17, 2490-2495.

17 W.-W. Wang and J.-L. Yao, Mater. Res. Bull., 2012, 47, 17621767.

18 L. Xi, S. Y. Chiam, W. F. Mak, P. D. Tran, J. Barber, S. C. J. Loo and L. H. Wong, Chem. Sci., 2013, 4, 164-169.

19 T. H. Jeon, A. D. Bokare, D. S. Han, A. Abdel-Wahab, H. Park and W. Choi, Appl. Catal., B, 2017, 201, 591-599.

20 L. Yichuan and L. Yat, Part. Part. Syst. Charact., 2014, 31, 1113-1121.

21 S. Shen, S. A. Lindley, X. Chen and J. Z. Zhang, Energy Environ. Sci., 2016, 9, 2744-2775.

22 V. O. Williams, E. J. DeMarco, M. J. Katz, J. A. Libera, S. C. Riha, D. W. Kim, J. R. Avila, A. B. F. Martinson, J. W. Elam, M. J. Pellin, O. K. Farha and J. T. Hupp, ACS Appl. Mater. Interfaces, 2014, 6, 12290-12294.

23 Y.-F. Xu, H.-S. Rao, X.-D. Wang, H.-Y. Chen, D.-B. Kuang and C.-Y. Su, J. Mater. Chem. A, 2016, 4, 5124-5129.

24 Z. Zhang, C. Gao, Y. Li, W. Han, W. Fu, Y. He and E. Xie, Nano Energy, 2016, 30, 892-899.

25 K. Kim, I.-H. Kim, K.-Y. Yoon, J. Lee and J.-H. Jang, J. Mater. Chem. A, 2015, 3, 7706-7709.

26 Y. Qiu, S.-F. Leung, Q. Zhang, B. Hua, Q. Lin, Z. Wei, K.-H. Tsui, Y. Zhang, S. Yang and Z. Fan, Nano Lett., 2014, 14, 2123-2129.

27 H. Hyungkyu, K. Stepan, K. Frantisek, W. Lei, N. Alberto, S. Patrik and Z. Radek, Small, 2018, 14, 1703860.

28 X. Yang-Fan, R. Hua-Shang, C. Bai-Xue, L. Ying, C. HongYan, K. Dai-Bin and S. Cheng-Yong, Adv. Sci., 2015, 2, 1500049.

29 L. N. Quan, Y. H. Jang, K. A. Stoerzinger, K. J. May, Y. J. Jang, S. T. Kochuveedu, Y. Shao-Horn and D. H. Kim, Phys. Chem. Chem. Phys., 2014, 16, 9023-9030.

30 Y. Yu, J. Quan, M. Dan, Q. Jian, W. Yanze, Y. Ranbo, L. Anran, L. Shuzhou, Z. Huijun, M. Yanwen, W. Lianhui, H. Wenping and W. Dan, Adv. Mater., 2017, 29, 1604795.

31 C. Xiaobo, Z. Haifeng and C. Chuanwei, Semicond. Sci. Technol., 2017, 32, 114003.

32 K. Yu, C. Zhang, Y. Chang, Y. Feng, Z. Yang, T. Yang, L.-L. Lou and S. Liu, Appl. Catal., B, 2017, 200, 514-520.

33 M. Zhou, J. Bao, Y. Xu, J. Zhang, J. Xie, M. Guan, C. Wang, L. Wen, Y. Lei and Y. Xie, ACS Nano, 2014, 8, 7088-7098.

34 Y. Gun, G. Y. Song, V. H. V. Quy, J. Heo, H. Lee, K.-S. Ahn and S. H. Kang, ACS Appl. Mater. Interfaces, 2015, 7, 20292-20303. 35 M. Ma, J. K. Kim, K. Zhang, X. Shi, S. J. Kim, J. H. Moon and J. H. Park, Chem. Mater., 2014, 26, 5592-5597. 
36 K.-Y. Yoon, J.-S. Lee, K. Kim, C. H. Bak, S.-I. Kim, J.-B. Kim and J.-H. Jang, ACS Appl. Mater. Interfaces, 2014, 6, 2263422639.

37 I. Kondofersky, H. K. Dunn, A. Müller, B. Mandlmeier, J. M. Feckl, D. Fattakhova-Rohlfing, C. Scheu, L. M. Peter and T. Bein, ACS Appl. Mater. Interfaces, 2015, 7, 4623-4630. 38 P. Jiang, J. F. Bertone, K. S. Hwang and V. L. Colvin, Chem. Mater., 1999, 11, 2132-2140.

39 L. Vayssieres, N. Beermann, S.-E. Lindquist and A. Hagfeldt, Chem. Mater., 2001, 13, 233-235.

40 A. M. Xavier, F. F. Ferreira and F. L. Souza, RSC Adv., 2014, 4, 17753-17759.

41 X. Chen, J. Ye, S. Ouyang, T. Kako, Z. Li and Z. Zou, ACS Nano, 2011, 5, 4310-4318.

42 K. Kim, P. Thiyagarajan, H.-J. Ahn, S.-I. Kim and J.-H. Jang, Nanoscale, 2013, 5, 6254-6260.

43 Q. Zeng, J. Bai, J. Li, L. Xia, K. Huang, X. Li and B. Zhou, J. Mater. Chem. A, 2015, 3, 4345-4353.
44 Y. Zhang, J. Cai, Y. Ma and L. Qi, Nano Res., 2017, 10, 26102625.

45 V. Müller, M. Rasp, G. Štefanić, J. Ba, S. Günther, J. Rathousky, M. Niederberger and D. Fattakhova-Rohlfing, Chem. Mater., 2009, 21, 5229-5236.

46 K. L. Purvis, G. Lu, J. Schwartz and S. L. Bernasek, J. Am. Chem. Soc., 2000, 122, 1808-1809.

47 M. Ji, J. Cai, Y. Ma and L. Qi, ACS Appl. Mater. Interfaces, 2016, 8, 3651-3660.

48 A. Subramanian, E. Gracia-Espino, A. Annamalai, H. H. Lee, S. Y. Lee, S. H. Choi and J. S. Jang, Appl. Surf. Sci., 2018, 427, 1203-1212.

49 J.-J. Wang, Y. Hu, R. Toth, G. Fortunato and A. Braun, J. Mater. Chem. A, 2016, 4, 2821-2825.

50 S. C. Riha, M. J. DeVries Vermeer, M. J. Pellin, J. T. Hupp and A. B. F. Martinson, ACS Appl. Mater. Interfaces, 2013, 5, 360367. 